other. The classification of birds has been based on habit rather than anatomy; this need not detract from the zoological value of the book.

The text itself is pithy and relevant, and, besides interesting details about the habits and life-histories of the animals described, introduces items of economics, history, geography and heraldry when these are of current interest.

If this book has a flaw, it is in the way the stamps themselves are displayed. More than 290 stamps are illustrated on a central set of thirty-three plates. These are all in black-and-white and are not always clear. Yet it is the rich colour of the original stamp that one misses-as the attractively coloured dustcover confirms - and one can only assume that the inclusion of colour plates would have made the price of the book too high. Now that the quality of colour reproduction has reached a high level, however, the authors might have reached a bigger audience if, say, they had confined the animals depicted to the vertebrates and illustrated their stamps in colour. Stamp-saving schoolboys and philatelic adults would have found such a book irresistible. Yet until such a book is produced they will be well content with "Zoology in Postage Stamps", which has grown from the commendable initiative of its authors and publishers.

T. H. Hawkins

\section{INTRODUCTION TO COLLOID SCIENCE}

\section{Colloid Science}

By Prof. James W. McBain. Pp. xiv+450. (Boston, Mass.: D. C. Heath and Co.; London: George G. Harrap and Co., Ltd., 1950.) 30s. net.

HIS volume by one of the chief workers in the field, with a foreword by Prof. Arthur B. Lamb, is a readable contribution to the ever-growing literature on the subject which is now termed colloid science. It is now generally accepted that the purely descriptive subject of colloids, which was so clearly recognized by Thomas Graham, was put on a much firmer foundation as an exact subject by two important discoveries : the quantitative formulation of the laws of adsorption at an interphase by Willard Gibbs, and the concept of the orientated monolayer as constituting that interphase introduced almost simultaneously but from different points of view by Devaux in France, Sir William Hardy in Britain, and Irving Langmuir in the United States.

Prof. J. W. McBain covers a very wide field in some twenty-seven chapters. The arrangement of the book is admirable. After a brief introduction in which an early chapter is given to the phenomenon of sorption and one to the effective depth of surfaces, the subject is treated in a systematic manner. Exception might be taken to the discussion on emulsions and foams preceding the more general portions of the subject. As might have been anticipated, Chapters 17, 18 and 19, which comprise the subjects to which the author has contributed so much, namely, colloidal electrolytes, protein solutions and non-aqueous colloids, are excellent for their clarity of style.

There must be many who would like to know what colloid science is about, and for such this is an excellent book. For in it one finds a good description of its purpose and of the widespread manifestations of the colloid state. While books of this kind are welcome, they also constitute a danger in that the descriptive parts on colloids and colloid properties still far outrun our exact knowledge and the strictly quantitative aspects of the subject, and it is on these latter that the survival of this, one of the youngest of the scientific family, will ultimately depend.

The volume is well printed, and for a modern book is not unduly expensive.

ERIC K. RIDeAL

\section{PSYCHOANALYSIS AND HAIR}

\section{The Unconscious Significance of Hair}

By Dr. Charles Berg. Pp. vi+106. (London : George Allen and Unwin, Ltd., 1951.) 15s. net.

W the preface to this interesting monograph, Dr. 1 Charles Berg points out that it is a study which "is really a psychiatric criticism of normality based on a chosen item of typically normal behaviour. . . . Hair activities are chosen merely as a sample of uncritically accepted human behaviour. On examining them in the light of dreams, anthropology, folklore, symptoms and perversions, they are shown to be an expression of instinct-driven tensions and conflicts".

The author discusses normal hair behaviour and suggests its importance by quoting the estimate that there are ten thousand hairdressing establishments in the Metropolitan Police Area of London. Women spend $£ 30,000,000$ a year on permanent waving alone. He proceeds to produce clinical evidence from patients' drcams and associations to show that hair is related to sexuality in the unconscious mind, and that cutting it is the unconscious equivalent of castration. He produces also anthropological evidence to support this view, as well as calling on folk-lore and legend. Further evidence suggests pregenital factors are concealed in the emotions concerned with hair, and this is supported by the behaviour in erotic perversions and fetishism. Dr. Berg adheres to the strict psychoanalytical view, and, indeed, his book is a reliable outline of these theories.

There is no doubt that patients do have dreams similar to those described in the book and do produce associations like those which are given. The loss of hair, like the pulling of teeth, is associated with a deprivation which is regarded as a sexual loss. That is, it is unconsciously equated with castration. However, there are other factors concerned in some of the perversions. For example, in exhibitionism there is often a positive seeking of love rather than a denial of castration, and this accords with the exhibitionistic behaviour of the anthropoid when he parades beating his chest before the female. It is a pity that once or twice Dr. Berg quotes an outmoded authority such as Havelock Ellis rather than going to more recent sources. For example, regarding pigmentation and hair on the body signifying hypersexuality, the endocrinologist would point to adrenogenital virilism, and Addison's disease and so on, where it definitely does not do so. However, these are minor matters. The author succeeds in what he attempts to do-that is, give an account of the psychoanalytical theories regarding hair, and the book is well worth reading for those interested in it. The style is clear and erudite. It is well printed on non-shiny paper and well bound in a light-blue colour.
Cliffrord Allen 